Chioma N. P Mbachu*, Joy C. Ebenebe, Ikechukwu I. Mbachu, Chizalu I. Ndukwu, Jacinta C. Elo-Ilo, Chimaobi M. Azubuike, Victoria C. Ofora and Richard Uwakwe

\title{
Sociodemographic profile of psychoactive substance use among selected secondary school students in rural Nigeria
}

https://doi.org/10.1515/ijamh-2020-0086

Received April 23, 2020; accepted June 7, 2020; published online September 2, 2020

\section{Abstract}

Objectives: Use of Psychoactive substances by young people poses an important public health threat despite mass campaigns and education. There have been documentations of rise in prevalence and use of psychoactive substances by Nigerian adolescents in urban areas of Nigeria. Few reports exist on in-school adolescents in rural areas, and differences in their sociodemographic profile such as public/private school attendance, day/boarding status and socioeconomic status of students. The study determined the rate and sociodemographic profile of psychoactive substance use among secondary school students in selected rural communities in Anambra state, Nigeria.

Methods: This was a cross-sectional study in which multistage sampling was used to select 494 students from selected secondary schools in Anambra state. Data on age, gender, socioeconomic status, student status, school category, alcohol, tobacco and intravenous drug use were obtained using pretested semi-structured questionnaires. Analysis of data was done using IBM SPSS statistics

*Corresponding author: Chioma N. P. Mbachu, MBBS, FWACP(Paed), Lecturer/ Consultant, Department of Paediatrics, Nnamdi Azikiwe University, Awka, Nigeria,

E-mail: chiomambachupauline@gmail.com. https://orcid.org/00000001-7030-5828

Joy C. Ebenebe, Chizalu I. Ndukwu and Jacinta C. Elo-Ilo, Department of Paediatrics, Nnamdi Azikiwe University, Awka, Nigeria,

E-mail: jc.ebenebe@unizik.edu.ng (J.C. Ebenebe), ifeyc@yahoo.com (C.I. Ndukwu), jc.elo-ilo@unizik.edu.ng (J.C. Elo-Ilo)

Ikechukwu I. Mbachu, Department of Obstetrics and Gynaecology, Nnamdi Azikiwe University, Awka, Nigeria,

E-mail: ii.mbachu@unizik.edu.ng. https://orcid.org/0000-0001-

7779-4388

Chimaobi M. Azubuike and Victoria C. Ofora, Department of Paediatrics, Nnamdi Azikiwe University Teaching Hospital, Nnewi, Nigeria, E-mail: chimaobing@yahoo.com (C.M. Azubuike), victoriaofora1@gmail.com (V.C. Ofora)

Richard Uwakwe, Department of Mental Health, Nnamdi Azikiwe University, Awka, Nigeria, E-mail: ruwakwe2001@yahoo.com software version 20.0, frequency, percentages and means were calculated, with cross-tabulation done for variables (Chi-square and Fishers exact test where applicable). Level of significance for tests of association set at 5\%.

Results: A total of 494 participants were studied of which 48.8\% ( $\mathrm{n}=241)$ were males. The mean age was $14.5 \pm 1.8$ years. The prevalence of lifetime use of psychoactive substance was $22.5 \%$. Prevalence for individual substances were $21.9 \%(\mathrm{n}=108), 1.8 \%(\mathrm{n}=9)$ and $0.8 \%(\mathrm{n}=4)$ respectively for alcohol, tobacco and illicit intravenous drugs. Neither gender $\{6$ males (2.5\%), 3 females $(1.2 \%), p=0.890\}$, age $\{10-13$ years $(1.3 \%), 14-16$ years $(2.1 \%),>16$ years $(1.7 \%), \mathrm{p}=0.329\}$, student status \{day $(2.6 \%)$, boarding $(1.2 \%), p=0.320\}$, social class \{upper $(0.9 \%)$, middle $(0.6 \%)$, lower (3.1\%), $\mathrm{p}=0.208$ \} nor school category \{private $(1.5 \%)$, public $(2.1 \%), p=0.742\}$ of students was significantly associated with smoking and respectively. More males $(73 / 241=30.3 \%, \mathrm{p}<0.001)$ took alcohol than females $(35 / 253=13.8 \%)$ and this was statistically significant. Participants from the lower socioeconomic class $(30.3 \%, \mathrm{p}<0.001)$ had a significantly higher rate of alcohol consumption than those from the upper $(11.8 \%)$ and middle classes $(16.7 \%)$ respectively. Higher rate was noted among those who attended public schools (30.8\%, $\mathrm{p}<0.001)$ compared to those who attended private schools $(13.8 \%)$. Day students $(30.2 \%, \mathrm{p}<0.001)$ indulged more in alcohol than boarding students (14.3\%). There was no association between either the class (junior= $22.5 \%$, senior $=21.3 \%, \mathrm{p}=0.759$ ) or age of participants $(10-13$ years $=20.7 \%, 14-16$ years $=20.1 \%,>16$ years $=33.3 \%$, $\mathrm{p}=0.071$ ) and alcohol consumption. No association was found between age $(0.7 \%, 1.1 \%, \mathrm{p}=1.000)$, gender (male $=1.2 \%$, female $=0.4 \%, \quad \mathrm{p}=0.362$ ), social class (lower $=1.3 \%$, upper $=0.9 \%, \quad \mathrm{p}=0.443$ ), student status (day $=0.9 \%$, boarding $=0.8 \%, \mathrm{p}=1.000$ ), school category (junior $=0.8 \%$, senior $=0.8 \%, \mathrm{p}=1.000$ ) and intravenous drug use.

Conclusions: The rate of about $22 \%$ alcohol use by secondary school students in rural south eastern Nigeria, which is strongly associated with male gender, low socioeconomic status, day student status and public school attendance is high. 
Keywords: adolescents; psychoactive; rural area; substance use.

\section{Introduction}

Use of Psychoactive substances continues to be on the increase in our world today and poses a serious public health challenge despite health campaigns [1-3]. Annually, it is estimated that greater than 270 million people globally use psychoactive substances, with adolescents contributing significantly to these rising trend in rates $[1,4,5]$. It is also known that these substances have negative effects on the general health and well-being of users in addition to usurping a large amount of economic resources. Furthermore, illicit drugs have been observed to be a risk factor for major depressive disorder and suicide among adolescents and adults with some authors citing its strong association with increased morbidity and mortality [6, 7]. Adolescence is a period of transition from childhood to adulthood that is not only sensitive and vulnerable, but may also affect outcome in later years. It is a formative period when there is rapid growth, development and self-discovery. Positive habits and experiences garnered enhance overall wellbeing whereas negative ones result in poor outcomes $[8,9]$. Thus, this group is very critical in any policy making to improve health outcomes and reduce disease burden on the populace.

Rates of psychoactive substance use may vary from one area of the country to the other. Anochie and Nkanginieme [10] reported between 0.8 and $32.1 \%$ among senior secondary students in an urban city in South-South Nigeria. In a similar Nigerian study by Fatoye et al. [11] among secondary school students in South-West Nigeria, prevalence rates of drug use reported was between 0.5 and $72.1 \%$. However, they studied only senior secondary school students. Abdulkarim et al. [12] reported drug use rate of 40.1\% in urban secondary school students in North-Central Nigeria. In urban secondary schools in a South-Eastern city, rate of psychoactive substance use reported by Igwe et al. [13] was $29.5 \%$. The study was conducted among mainly senior secondary students. Rate of psychoactive substance use reported by Egbuonu et al. [14] in a study among female senior secondary students in a SouthEastern Nigerian state was $29.5 \%$. The study group was a non- homogenous group which included adolescents and young adults up to 25 years. Several sociodemographic factors such as gender, social class, class in school, religiosity, pressure by peers and relationship with family members have been associated with use of psychoactive substances $[10,11,15,16]$. Siblings and family use of substances, and favorable community norms have been associated with substance use among adolescents in Ethiopia [17]. Anochie and Nkanginieme [10] reported infrequent Christian religious practice, gender and nonstandard families (single parenthood, separated homes and poor supervision) as correlates of illicit drug use. Age, social class and poor participation in religious activities have also been implicated as contributing to substance use among adolescents [16]. Many studies in Nigeria have focused mainly on senior secondary students in urban centers. Few have been done in rural areas. There is a need to understand other demographics affecting substance use in adolescents including type of school in terms of day and boarding, public and private schools. Periodic reviews are important in determining the pattern, and risk factors for provision of data needed for health education of this important group of people. Thus, this study was carried out to determine the use of psychoactive substances among secondary school boys and girls in selected secondary schools in Anambra state.

\section{Materials and methods}

This was a cross-sectional study conducted among secondary school students in Anambra State from April to July, 2017.

Multi-stage sampling was used to select students from all classes (JSS1 - SS3) in selected secondary schools in Anambra state. Minimum sample size of 444 was calculated using a prevalence of $29.5 \%$ in a previous study in Anambra by Egbuonu et al. [14] to achieve a power of $80 \%$, precision of $95 \%$ and assuming a non-response rate of $20 \%$. A total of 494 students were studied. To ensure a good mix, co-educational and same sex schools; male and female gender; classes were selected using stratified sampling method. Random sampling was used to select classes to be studied. This was followed by selection of participants in each class by simple random sampling using the class register as the sampling frame. A total of six schools participated in the study comprising three public and three private schools. The total population of students in the 21 private schools was 1,212 while that of students in the eight public schools was 1,117 giving a ratio of approximately 1:1. The selection was based on the population of the schools. Participants that opted out of the study were replaced by simple random sampling using balloting technique. Inclusion criteria was secondary school students from 10 to 18 years who gave consent/ assent for the study.

Ethical approval was obtained from the Ethics committee of Nnamdi Azikiwe University Teaching Hospital, Nnewi (NAUTH/CS/ 66/VOL. 9/154/2016/127). Permission was also obtained from the Ministry of Education, Anambra state (MOE/SCHD/1570/VOL.I/64), Post Primary School Board and the authorities of the secondary schools where the research was conducted. Informed consent/assent were also obtained from participants and their guardians. The Study was carried out in accordance with the code of ethics of the World 
Medical Association (Declaration of Helsinki) for research involving humans.

A pretested semi structured questionnaire was used to obtain relevant data. These included age of the participants, student status (whether boarding student or day student), gender, class, parents educational level and occupation (which was used to determine socioeconomic status using Oyedejis classification) [18], alcohol consumption, tobacco use, intravenous drug use.

\section{Data analysis}

Data was analyzed using IBM SPSS statistics software version 20.0. Numerical variables like age was summarized using mean and standard deviation. Age was further categorized during analysis into early, middle and late adolescence. Categorical variables (gender, student status, class category, socioeconomic status, school category) were summarized using frequency and percentages. Cross tabulation was used to determine the association between socio demographic variables (gender, age group, socioeconomic status, student status, class category and school category) and substance use, using Chi Square. Where applicable, Fishers exact test was used to test association between these variables. Level of significance for tests of association was set at $\mathrm{p}$-value of less than 0.05 .

\section{Results}

A total of 494 students participated in this study, comprising 241 males (48.8\%). The mean age was (14.5 \pm 1.8 years). About half of the participants (52.4\%) were boarding students. Similarly, students from senior secondary class category constituted almost half of participants 258 (52.2\%) while 235 (47.6\%) were from junior secondary classes. Participants from the lower socioeconomic class made up about 228 (46.2\%) of the population. Table 1 shows the sociodemographic characteristics of participants. The prevalence of psychoactive substance use among the participants was $111(22.5 \%)$. The commonest substance used was alcohol 108 (21.9\%). Only 9 $(1.8 \%)$ participants used tobacco while $0.8 \%$ used intravenous substances.

Only 75/241 (31\%) of male participants admitted to use of at least one substance compared to 36/253 (14\%) of females who reported drug use (36/253). Gender was significantly associated with use of psychoactive substance $(\mathrm{p}<0.001)$. More participants from the lower socioeconomic class 71/228 (31.1\%) indulged in substance use, compared to $12 / 110(10.9 \%)$ of participants from the upper class and 28/156 (17.9\%) from the middle class respectively. This was found to be statistically significant $(p<0.001)$. Only $74 / 234$ (31\%) of students who attended public schools used substances compared to 37/260 (14\%) of their colleagues who attended private schools and this was statistically
Table 1: Sociodemographic characteristics of participants.

\begin{tabular}{lrr}
\hline Variable & Frequency & Percentage \\
\hline Gender & 242 & 48.8 \\
Male & 253 & 51.2 \\
Female & & \\
Age category & 150 & 30.4 \\
$10-13$ & 284 & 57.5 \\
$14-16$ & 60 & 12.1 \\
>16 & & \\
Class & 236 & 47.8 \\
Junior & 258 & 52.2 \\
Senior & & \\
Student status & 259 & 52.4 \\
Boarding & 235 & 47.6 \\
Day & & \\
Socioeconomic class & 110 & 22.3 \\
Upper & 156 & 31.6 \\
Middle & 228 & 46.2 \\
Lower & & \\
School category & 260 & 52.6 \\
Private & 234 & 47.4 \\
Public & 494 & 100.0 \\
Total & & \\
\hline
\end{tabular}

significant $(\mathrm{p}<0.001)$. More day students $73 / 235$ (31\%) used psychoactive drugs when compared to boarding students $38 / 259(14 \%)(p<0.001)$. Neither class category $(p=0.670)$, nor age group ( $\mathrm{p}=0.098)$ of participants was significantly associated with psychoactive substance use. Table 2 shows the relationship between sociodemographic factors and substance use by participants.

There was significant association $(\mathrm{p}<0.001)$ between gender and alcohol use, with 73/241 (30.3\%) of male students admitting to alcohol use while $35 / 253$ (13.8\%) of female students consumed alcohol. Seventy-two of the two hundred and 30 students (30.8\%) who attended public schools took alcohol compared to 36/260 (13.8\%) private school students and this was statistically significant $(\mathrm{p}<0.001)$. Sixty nine out of two hundred and twenty eight (30.3\%) participants from the lower socioeconomic class consumed alcohol compared to 13/110 (11.8\%) from the upper class and 26/156 (16.7\%) from the middle class and this was statistically significant $(p<0.001)$. About $71 / 235$ (30\%) of day students $(71 / 235)$ reported alcohol use, while 37/259 (14.3\%) of boarding students reported alcohol use $(\mathrm{p}<0.001)$. There was no significant association between class category and alcohol use ( $p=0.759)$. Age group of participants was not associated with alcohol use $(\mathrm{p}=0.071)$. See Table 3. No sociodemographic variable assessed had a significant relationship with tobacco use (see Table 4). There was no 
Table 2: Relationship between sociodemographic factors and substance use by participants.

\begin{tabular}{|c|c|c|c|c|c|}
\hline \multirow[t]{2}{*}{ Variable } & \multirow[t]{2}{*}{ Frequency } & \multicolumn{2}{|c|}{ Substance use } & \multirow[t]{2}{*}{$x^{2}$} & \multirow[t]{2}{*}{ p-Value } \\
\hline & & Yes & No & & \\
\hline \multicolumn{6}{|l|}{ Gender } \\
\hline Male & 241 & $75(31.1)$ & $166(68.9)$ & 20.214 & $<0.001^{\mathrm{a}}$ \\
\hline Female & 253 & $36(14.2)$ & $217(85.8)$ & & \\
\hline \multicolumn{6}{|c|}{ Age group } \\
\hline $10-13$ & 150 & $32(21.3)$ & 118 (78.7) & 4.6444 & 0.098 \\
\hline $14-16$ & 284 & $59(20.8)$ & $225(79.2)$ & & \\
\hline$>16$ & 60 & $20(33.3)$ & $40(66.7)$ & & \\
\hline \multicolumn{6}{|c|}{ School category } \\
\hline Private & 260 & $37(14.2)$ & $223(85.8)$ & 21.387 & $<0.001^{\mathrm{a}}$ \\
\hline Public & 234 & $74(31.6)$ & $160(68.4)$ & & \\
\hline \multicolumn{6}{|c|}{ Class category } \\
\hline Junior & 236 & $55(23.3)$ & $182(76.7)$ & 0.181 & 0.670 \\
\hline Senior & 258 & $56(21.7)$ & 202 (78.3) & & \\
\hline \multicolumn{6}{|c|}{ Student status } \\
\hline Boarding & 259 & 38 (14.7) & $221(85.3)$ & 19.004 & $<0.001^{\mathrm{a}}$ \\
\hline day & 235 & $73(31.1)$ & $162(68.9)$ & & \\
\hline \multicolumn{6}{|c|}{ Socioeconomic class } \\
\hline Upper & 110 & $12(10.9)$ & $98(89.1)$ & 20.109 & $<0.001^{\mathrm{a}}$ \\
\hline Middle & 156 & 28(17.9) & $128(82.1)$ & & \\
\hline Lower & 228 & $71(31.1)$ & $157(68.9)$ & & \\
\hline Total & 494 & $111(22.5)$ & $383(77.5)$ & & \\
\hline
\end{tabular}

${ }^{a}$ significant $p$-Value.

significant association between sociodemographic variables and intravenous drug use (see Table 5).

\section{Discussion}

Substance use is a challenge in rural communities as demonstrated by the high prevalence of $22.5 \%$ obtained in this study. This agrees with finding by Igwe et al. [13] in Enugu who reported a rate of $29.5 \%$ among secondary school students. However, higher values of 87.3 and $40.1 \%$ were reported by Oshodi et al. [3] in school adolescents in Surulere, a cosmopolitan city in Lagos. Abdulkarim et al. [19] in Ilorin also reported higher rate than that obtained in this study. The difference in rates could be because their studies were conducted among students living in very large urban cities where there is easy access to illicit substances through street boys/urchins popularly called area boys. Our study found alcohol to be the highest substance used (21.9\%) similar to the report by Anochie and Nkanginieme [10]. One possible reason for the high prevalence of alcohol use in our study may be that alcohol is socially acceptable, locally brewed and easily accessible. Contrary findings have been given by some other authors who reported analgesics and stimulants as being top on the list of
Table 3: Relationship between sociodemographic factors and alcohol use by participants.

\begin{tabular}{|c|c|c|c|c|c|}
\hline \multirow[t]{2}{*}{ Variable } & \multirow[t]{2}{*}{ Frequency } & \multicolumn{2}{|r|}{ Alcohol use } & \multirow[t]{2}{*}{$x^{2}$} & \multirow[t]{2}{*}{ p-Value } \\
\hline & & Yes & No & & \\
\hline \multicolumn{6}{|l|}{ Gender } \\
\hline Male & 241 & $73(30.3)$ & $168(69.7)$ & 19.567 & $<0.001^{\mathrm{a}}$ \\
\hline Female & 253 & $35(13.8)$ & $218(86.2)$ & & \\
\hline \multicolumn{6}{|c|}{ Class category } \\
\hline Junior & 236 & $53(22.5)$ & $183(77.5)$ & 0.094 & 0.759 \\
\hline Senior & 258 & $55(21.3)$ & $203(78.7)$ & & \\
\hline \multicolumn{6}{|c|}{ School category } \\
\hline Private & 260 & $36(13.8)$ & $224(86.2)$ & 20.647 & $<0.001^{\mathrm{a}}$ \\
\hline Public & 234 & $72(30.8)$ & $162(69.2)$ & & \\
\hline \multicolumn{6}{|c|}{ Age group } \\
\hline $10-13$ & 150 & $31(20.7)$ & $119(79.3)$ & 5.281 & 0.071 \\
\hline $14-16$ & 284 & $57(20.1)$ & $227(79.9)$ & & \\
\hline$>16$ & 60 & $20(33.3)$ & $40(66.7)$ & & \\
\hline \multicolumn{6}{|c|}{ Socioeconomic class } \\
\hline Upper & 110 & $13(11.8)$ & $97(88.2)$ & 18.381 & $<0.001^{\mathrm{a}}$ \\
\hline Middle & 156 & $26(16.7)$ & $130(83.3)$ & & \\
\hline Lower & 228 & $69(30.3)$ & $159(69.7)$ & & \\
\hline \multicolumn{6}{|c|}{ Student status } \\
\hline Day & 235 & $71(30.2)$ & $164(69.8)$ & 18.296 & $<0.001^{\mathrm{a}}$ \\
\hline Boarding & 259 & $37(14.3)$ & $222(85.7)$ & & \\
\hline Total & 494 & $108(21.9)$ & $386(78.1)$ & & \\
\hline
\end{tabular}

${ }^{\mathrm{a}}$ significant $\mathrm{p}$-Value.

Table 4: Relationship between sociodemographic factors and tobacco use by participants.

\begin{tabular}{|c|c|c|c|c|c|}
\hline \multirow[t]{2}{*}{ Variable } & \multirow[t]{2}{*}{ Frequency } & \multicolumn{2}{|r|}{ Tobacco use } & \multirow[t]{2}{*}{$x^{2}$} & \multirow[t]{2}{*}{ p-Value } \\
\hline & & Yes & No & & \\
\hline \multicolumn{6}{|l|}{ Gender } \\
\hline Male & 241 & $6(2.5)$ & $235(97.5)$ & - & $0.329^{\mathrm{a}}$ \\
\hline Female & 253 & $3(1.2)$ & $250(98.8)$ & & \\
\hline \multicolumn{6}{|c|}{ Class category } \\
\hline Junior & 236 & $3(1.3)$ & $233(98.7)$ & - & $0.508^{\mathrm{a}}$ \\
\hline Senior & 258 & $6(2.3)$ & $252(97.7)$ & & \\
\hline \multicolumn{6}{|c|}{ Age group } \\
\hline $10-13$ & 150 & $2(1.3)$ & $148(98.7)$ & - & $0.890^{\mathrm{a}}$ \\
\hline $14-16$ & 284 & $6(2.1)$ & $278(97.9)$ & & \\
\hline$>16$ & 60 & $1(1.7)$ & $59(98.3)$ & & \\
\hline \multicolumn{6}{|c|}{ School category } \\
\hline Private & 260 & $4(1.5)$ & $256(98.5)$ & - & $0.742^{\mathrm{a}}$ \\
\hline Public & 234 & $5(2.1)$ & $229(97.9)$ & & \\
\hline \multicolumn{6}{|c|}{ Socioeconomic class } \\
\hline Upper & 110 & $1(0.9)$ & $109(99.1)$ & - & $0.208^{\mathrm{a}}$ \\
\hline Middle & 156 & $1(0.6)$ & $155(99.4)$ & & \\
\hline Lower & 228 & $7(3.1)$ & $221(96.9)$ & & \\
\hline \multicolumn{6}{|c|}{ Student status } \\
\hline Day & 235 & $6(2.6)$ & $229(97.4)$ & - & $0.320^{\mathrm{a}}$ \\
\hline Boarding & 259 & $3(1.2)$ & $256(98.8)$ & & \\
\hline Total & 494 & $9(1.8)$ & $485(98.2)$ & & \\
\hline
\end{tabular}

${ }^{a} \mathrm{p}$-Value using Fishers exact test. 
Table 5: Relationship between sociodemographic factors and intravenous drug use by participants.

\begin{tabular}{|c|c|c|c|c|c|}
\hline \multirow[t]{2}{*}{ Variable } & \multirow[t]{2}{*}{ Frequency } & \multicolumn{2}{|c|}{ Intravenous drug use } & \multirow[t]{2}{*}{$x^{2}$} & \multirow[t]{2}{*}{ p-Value } \\
\hline & & Yes & No & & \\
\hline \multicolumn{6}{|l|}{ Gender } \\
\hline Male & 241 & $3(1.2)$ & $238(98.8)$ & - & $0.362^{a}$ \\
\hline Female & 253 & $1(0.4)$ & $252(99.6)$ & & \\
\hline \multicolumn{6}{|c|}{ Class category } \\
\hline Junior & 236 & $2(0.8)$ & 234 (99.2) & - & $1.000^{\mathrm{a}}$ \\
\hline Senior & 258 & $2(0.8)$ & $256(99.2)$ & & \\
\hline \multicolumn{6}{|c|}{ Age group } \\
\hline $10-13$ & 150 & $1(0.7)$ & $149(99.3)$ & - & $1.000^{\mathrm{a}}$ \\
\hline $14-16$ & 284 & $3(1.1)$ & 281 (98.9) & & \\
\hline$>16$ & 60 & $0(0.0)$ & $60(100.0)$ & & \\
\hline \multicolumn{6}{|c|}{ School category } \\
\hline Private & 260 & $2(0.8)$ & $258(99.2)$ & - & $1.000^{\mathrm{a}}$ \\
\hline Public & 234 & $2(0.9)$ & $232(99.1)$ & & \\
\hline \multicolumn{6}{|c|}{ Socioeconomic class } \\
\hline Upper & 110 & $1(0.9)$ & 109 (99.1) & - & $0.443^{\mathrm{a}}$ \\
\hline Middle & 156 & $0(0.0)$ & $156(100.0)$ & & \\
\hline Lower & 228 & $3(1.3)$ & $225(98.7)$ & & \\
\hline \multicolumn{6}{|c|}{ Student status } \\
\hline Day & 235 & $2(0.9)$ & $233(99.1)$ & - & $1.000^{\mathrm{a}}$ \\
\hline Boarding & 259 & $2(0.8)$ & 257 (99.2) & & \\
\hline Total & 494 & $4(0.8)$ & 490(99.2) & & \\
\hline
\end{tabular}

${ }^{a} p$-Value using Fisher's exact test.

psychoactive substances used $[3,16,19,20]$. These studies were conducted among adolescents in the south western region of Nigeria with peculiar differences in sociocultural norms when compared to the south east. Further studies may be needed to explore these differences further. The use of alcohol was predominantly by males. This agrees with findings by Birhanu et al. [17], Manyike et al. [16], Anochie and Nkanginieme [10], Fatoye and Morakinyo [11]. Adolescent males are adventurous and exploratory, in addition to the fact that socioculturally, drinking is regarded as a male activity. Participants from the lower socioeconomic class indulged more in psychoactive substance use. This has also been reported by Azaiza et al. [21] among in school Arab adolescents in Israel. It could be that economic hardship faced by parents from the lower socioeconomic class, probable poor supervision of these students may give these students free access to these illicit substances. On the contrary, some authors have argued that free access to substances may be found more among people from the upper class because parents are too busy to supervise their children, in addition to children having greater purchasing power while, some others found no relationship between social class and drug use $[10,13,16$, 22]. In the present study, we found higher rate of substance use among day students compared to boarding students.
Boarding students are in a closed unit and frequently monitored in the boarding houses unlike day students, who may regularly explore with peers as adolescents are wont to do, and have free access to psychoactive substances after school hours. In addition, students from public schools had a higher rate of substance use than their counterparts who attended private schools. They also had higher rate of indulgence in alcohol. The reason for this is unclear but it could be linked to less discipline and supervision by teachers in Nigerian public schools when compared to private schools. Neither age group nor class category had significant association with substance use in contrast to findings by some authors $[11,16]$. This is probably because a homogenous group of adolescents was studied. Fatoye et al. [11] reported significant association between class and substance use, while Manyike et al. [16] also reported significant association between class, age and psychoactive substance use. Neither tobacco nor intravenous drugs was significantly associated with any of the sociodemographic variables likely because few participants admittedly used these substances. A different study design may be used to explore these factors.

\section{Conclusions}

There is high burden of psychoactive substance use especially alcohol by secondary school students in the rural south eastern part of Nigeria, with associated sociodemographic factors being male gender, day student status, attendance of public school and lower socioeconomic class status. There is need for further studies on substance use in more rural secondary schools in Nigeria, such that data collated can be used for surveillance and possible policy making in the future.

Research funding: The authors bore the full cost of the study.

Author contributions: The manuscript was conceived by MCNP, MII, EJC and URU. All the authors contributed to the study design. Data collection was done by MCNP, EJC, MII and EIJC, while data analysis was done by MCNP, ACM, OVC and NC. The initial draft was produced by MCNP, MII and ACM; and edited by URU, NC, EIJC and OVC. All authors are in agreement with the final edited manuscript. Competing interests: The authors declare no conflict of interest.

Informed consent: Informed consent document was signed prior to enrollment by parents/guardians. Assent was given by participants less than 18 years old. 
Ethical approval: This study was part of a larger study conducted among adolescents. Ethics approval and permission to conduct research were obtained prior to commencement of the study from the ethical review board of Nnamdi Azikiwe University teaching Hospital, Nnewi (NAUTH/CS/66/VOL. 9/154/2016/127) and Ministry of Education, Anambra state (MOE/SCHD/1570/VOL.I/64), respectively.

\section{References}

1. UNODC. World drug report 2019: pre-release to Member States. Vienna: UNODC; 2019.

2. Wright JD, Pearl L. Knowledge and experience of young people regarding drug abuse, 1969-89. Br Med J 1990;300:99-103.

3. Oshodi OY, Aina OF, Onajole AT. Substance use among secondary school students in urban setting in Nigeria. African J Psychiary 2010;13:52-7.

4. UNODC. World drug report 2017: pre-briefing to the Member States. United Nations Publ [Internet]; 2017:pp. 1-35. Available from: https://www.unodc.org/wdr2017/field/WDR_2017_ presentation_lauch_version.pdf.

5. Peacock A, Leung J, Larney S, Colledge S, Hickman M, Rehm J, et al. Global statistics on alcohol, tobacco and illicit drug use: 2017 status report. Addiction 2018;113:1905-26.

6. Substance Abuse and Mental Health Services Administration. Results from the 2011 National Survey on Drug Use and Health: Mental Health Findings, NSDUH Series H-45. HHS Publication No. (SMA) 12-4725; 2012. Available from: https://store.samhsa.gov/ home.

7. World Health Organization (WHO). ATLAS on substance use. Manegement Subst Abus [Internet] 2010;2010:156. Available from: https://www.who.int/substance_abuse/publications/ treatment/en/.

8. UNICEF. UNICEF Programme Guidance for the second decade: programming with and for adolescents; 2018. Available from: https://gallery.mailchimp.com/ fb1d9aabd6c823bef179830e9/files/4945e2fb-1282-48cdb2d1-049bd8797061/UNICEF_Programme_Guidance_for_the Second_Decade.pdf.

9. Bauman A, Phongsavan P. Epidemiology of substance use in adolescence: prevalence, trends and policy implications. Drug Alcohol Depend 1999;55:187-207.

10. Anochie IC, Nkanginieme KEO. Social correlatives of drug use among secondary school. Sahel Med J 2000;3:87-92.
11. Fatoye FO, Morakinyo 0 . Substance use amongst secondary school students in rural and urban communities in South Western Nigeria. East Afr Med J 2002;79:299-305.

12. Makanjuola AB, Daramola TO, Obembe AO. Psychoactive substance use among medical students in a Nigerian university. World Psychiatry [Internet] 2007;6:112-4. Available from: https://www.ncbi.nlm.nih.gov/pubmed/18235869\%0Ahttp:// www.pubmedcentral.nih.gov/articlerender.fcgi? artid=PMC2219911.

13. Igwe WC, Ojinnaka N, Ejiofor SO, Emechebe GO. Sociodemographic correlates of psychoactive substance abuse among secondary school students in Enugu, Nigeria. Eur J Soc Sci 2009; 12:277-83.

14. Egbuonu I, Ezechukwu CC, Chukwuka JO, Uwakwe R. Substance abuse among female secondary school students in Anambra state, South Eastern Nigeria. Nig J Clin Prac 2004;7:53-5.

15. Adelekan ML, Abiodun OA, Imouokhome-Obayan AO, Oni GA, Ogunremi 00. Psychosocial correlates of alcohol, tobacco and cannabis use: findings from a Nigerian university. Drug Alcohol Depend 1993;33:247-56.

16. Manyike PC, Chinawa JM, Chinawa AT, Obu HA, Nwokocha ARC, Odetunde OI. Correlates for psycho-active substance use among boarding secondary school adolescents in Enugu, South East, Nigeria. BMC Pediatr [Internet] 2016;16: 1-8.

17. Birhanu AM, Bisetegn TA, Woldeyohannes SM. High prevalence of substance use and associated factors among high school adolescents in Woreta Town, Northwest Ethiopia: multi-domain factor analysis. BMC Publ Health 2014;14:1-11.

18. Oyedeji GA. Socio-economic and cultural background of hospitalised children in Ilesha. Niger J Paediatr 1985;12:111-7.

19. Fatiregun AA, Kumapayi TE. Prevalence and correlates of depressive symptoms among in-school adolescents in a rural district in southwest Nigeria. J Adolesc [Internet] 2014;37: 197-203.

20. Abdulkarim AA, Mokuolu OA, Adeniyi A. Drug use among adolescents in Ilorin, Nigeria. Trop Doct 2005;35:225-8.

21. Fatoye FO, Morakinyo 0 . Substance use among Secondary Students in Urban and rural communities of South western Nigeria. East Afr Med J 2002;79:299-305.

22. Azaiza F, Bar-Hamburger R, Moran M. Psychoactive substance use among arab adolescents in Israel. J Soc Work Pract Addict 2008;8:21-43.

23. Pratta EMM, Santos MA. Adolescence and the Consumption of Psychoactive substances: the impact of the socioeconomic status. Rev Lat am Enfermagem 2007;15:806-11. 